\title{
Más allá de la Torre de Marfil: vinculaciones de la universidad y sus territorios
}

\author{
Giselle González y Cecilia Schneider
}

\section{RESUMEN}

Se analiza el rol de la universidad en la región metropolitana de Buenos Aires. En particular, se explora de qué manera participa la universidad en el desarrollo local. Se diseñó un enfoque conceptual multidisciplinar que combina elementos del análisis político-organizacional, de la innovación social y el desarrollo local. Se integraron datos de fuentes primarias y secundarias. Los resultados sugieren que la universidad es un actor relevante para el desarrollo territorial. Aunque su actuación aún es de baja intensidad. Si bien la universidad incorpora esta misión a su agenda, el desarrollo de iniciativas territoriales es frágil en términos regionales y sistémicos.

Palabras clave: política pública, territorio, universidad, Argentina.

Giselle González 


\title{
Além da Torre de Marfil: vinculações da universidade e seus territórios
}

\section{RESUMO}

Se analisa o papel da universidade na região metropolitana de Buenos Aires. Em particular, se explora de que maneira a universidade participa no desenvolvimento local. Foi elaborado um enfoque conceitual multidisciplinar que combina elementos da análise político-organizacional, da inovação social e do desenvolvimento local. Se integraram dados de fontes primarias e secundarias. Os resultados sugerem que a universidade é um ator relevante para o desenvolvimento territorial. Mesmo sendo sua atuação ainda de baixa intensidade. Se por um lado a universidade incorpora esta missão em sua agenda, o desenvolvimento de iniciativas territoriais é frágil em termos regionais e sistémicos.

Palavras chave: política pública, território, universidade, Argentina.

\section{Beyond the Ivory Tower: links between the university and its territories}

\begin{abstract}
This article analyzes the role of the university in the Buenos Aires metropolitan region. In particular, it explores how the university takes part in local development. A multidisciplinary conceptual approach was designed that combines elements of political-organizational analysis, social innovation and local development. Data from primary and secondary sources were integrated. The results suggest that the university is a significant actor for the territorial development, although its impact is still reduced. Even though the university incorporates this mission into its agenda, the development of territorial initiatives is fragile in regional and systemic terms.
\end{abstract}

Key words: public policy, territory, university, Argentina. 


\section{Introducción}

Durante las últimas décadas cobró relevancia, en el plano regional como internacional, la discusión acerca del "deber ser" de la universidad, cambiando la noción de la búsqueda de conocimiento por el conocimiento en sí, a un concepto instrumental en el cual las universidades deben servir a la sociedad, generando una contribución a la economía y mejorando las condiciones de vida de sus habitantes (Gibbons, 1998). Bajo una nueva cultura de responsabilización evaluativa y de mayor vinculación científica y tecnológica, se estimula que la universidad pueda insertarse en el entorno territorial con funciones más específicas y pertinentes.

Esta nueva perspectiva sobre las universidades plantea la necesidad de "revisar" el vínculo entre la universidad argentina y su entorno local, regional y nacional. Con particular atención a los cambios de orden global que han transformado el campo universitario hacia una cultura de innovación y accountabilty a partir de cuyo escenario parece proyectarse la universidad argentina. Esta tendencia, que no es exclusiva de la Argentina sino de la región latinoamericana en general, ha llevado a muchos autores a vincular los sistemas universitarios de América Latina con "modelos urbanos de regionalización" en donde las dinámicas y sujetos políticos quedan definidos en el rango de las grandes ciudades capitales (Rama, 2015).

Este proceso ha asumido características particulares en las áreas metropolitanas debido a que concentran la mayor cantidad de instituciones así como una mayor densidad demográfica, cultural y económica.

La universidad en Argentina y sobre todo la Universidad de Buenos Aires (UBA), asumió desde sus orígenes un perfil profesionalista vinculado a la enseñanza para la formación de cuadros técnicos y para la dirigencia política, con una importancia menor a la producción de investigación pura. Esta orientación, que la acercó al denominado modelo de universidad francés o napoleónico, comenzó a ser objeto de debate al fundarse la Universidad Nacional de La Plata (UNLP) en 1890. La UNLP se diseñó con la intención de dar mayor importancia a la investigación y a su vinculación con el entorno territorial. La evolución y crecimiento del sistema universitario fue variando esta tendencia hacia modelos híbridos de docencia e investigación con una mayor apertura al territorio. Las últimas décadas han sido testigos de una mayor federalización del sistema público universitario que creció cuantitativamente aunque, a juicio de algunos autores, no modernizó sus estructuras académicas (González, 2013; García de Fanelli, 2005).

El territorio, entendido como un sistema de interacciones sociales históricamente estructuradas y en constante evolución, adquiere un rol vital para comprender y formular alternativas de desarrollo y políticas públicas nacionales. Los niveles locales o municipales adquieren el poder de imbricarse en la trama territorial y resolver problemas concretos como escala territorial más próxima (Subirats, 2016; Taquini et al., 2014).

Hasta no hace mucho, varias universidades se describían a sí mismas como cuerpos legales independientes de los Estados y sus territorios. En la actualidad, prácticamente la totalidad de ellas y en particular las universidades de última generación, presentan una vocación de compromisos para con ellos y el gran desafío es, entonces, cómo armonizar la construcción de enlaces con tales compromisos.

La importancia radica en la sinergia que genera el impulso múltiple de renovación y mejora: universidad como institución — sistema universitario - del área local, junto con instrumentos claves de redistribución, como forma de equilibrar las desigualdades que genera la dinámica de libre mercado en las diferentes regiones y más aún en aquellas con fuertes asimetrías internas y desigualdades, en términos de capacidades de infraestructura y equipamiento social. 
La actuación de las universidades en el contexto territorial y el reconocimiento de su papel en este ámbito plantean la necesidad de verificar si estas iniciativas han sido acompañadas de la construcción de capacidades efectivas para ejercer el rol de actores influyentes a nivel local. En este sentido, el propósito central del trabajo es explorar el rol de la universidad argentina y pública en su entorno territorial de pertenencia, desde una perspectiva que valora su vinculación y la transferencia de conocimiento.

A partir de allí, surgen otro conjunto de preguntas específicas tales como: ¿Cuál es el lugar que ocupa la problemática territorial en la agenda universitaria? ¿Cuáles son las iniciativas que promueve la universidad? ¿Qué espacios de participación y arreglos institucionales habilita para el diálogo con otros actores locales? ¿Qué capacidades y competencias domina para descifrar contextos y actores estratégicos?

Este artículo explora a la universidad pública argentina en su vínculo con el territorio. Al respecto, constituyen antecedentes importantes para pensar esta relación los aportes de Jorge Sábato, quien durante la década de los sesenta analizó la vinculación entre academia, Estado e industria a partir del concepto de "Triple Hélice". Allí postula un modelo de dependencia tecnológica en donde el Estado diseña y ejecuta la política pública, el mercado demanda tecnología y las universidades (los actores académicos) proveen los recursos e infraestructura. El concepto de la Triple Hélice (Sábato y Botana, 1968) incorpora la evolución en las relaciones entre universidades, empresas y gobierno, resaltando los nuevos papeles que estas esferas institucionales tempranamente comienzan a desempeñar. Sin embargo, los cambios en la matriz estado y el pasaje hacia modelos caracterizados por la pluralidad institucional han dejado desactualizadas estas ideas.

Más recientemente, los aportes de Federico Vasen (2008 y 2012) y de Sergio Emiliozzi (2012) indagan críticamente la función social de la universidad en su relación con el territorio y la productividad tecnológica desde una línea que busca marcar agendas de innovación responsable para los países en desarrollo.

Desde otros grupos de trabajo, se problematiza el papel regional de las universidades, mostrando tipos de desempeño de acuerdo con el comportamiento asociativo y estratégico (o no) de diferentes instituciones (Fernández Lamarra, 2015; Martínez Porta, 2014; González, 2013). No obstante, existen pocos estudios que busquen visibilizar las iniciativas de las nuevas universidades - creadas entre 2003 y 2015de la región metropolitana de Buenos Aires. En este sentido, el artículo apunta a cubrir esta área de vacancia. Para dar respuesta a los interrogantes planteados, el trabajo se organiza en cinco apartados. El primero desarrolla la perspectiva teórico-metodológica que utiliza el estudio. Las secciones subsiguientes examinan un conjunto de atributos del campo universitario, entendiendo que éstos pueden incidir en el desarrollo de la función social/tecnológica prevista para la universidad. La sección dos presenta las características del sistema universitario y algunos indicadores relativos a la organización. La tercera sección analiza sus capacidades y recursos. Allí se valoran capacidades jurídico-normativas: a) las reglas formales del sistema y su incidencia en la región metropolitana sur, b) la capacidad del presupuesto universitario de la región seleccionada, y c) recursos político-organizacionales. Hacia el final (sección cuarta) se plantea una discusión entre los incentivos en términos de sistema universitario y las políticas institucionales de las universidades nacionales. En la sección quinta, unas breves reflexiones finales.

\section{Algunas precisiones conceptuales}

El estudio se propone explorar de qué modo se vincula la universidad con su territorio. Para ello toma elementos conceptuales del análisis institucional, de la innovación social y del desarrollo local, entre los cuales se destaca el vínculo entre universidad y su entorno de pertenencia. 
El análisis del caso se enmarca en el contexto de las políticas públicas implementadas durante las últimas dos décadas, sin desconocer las políticas de regionalización de otros periodos previos. El marco analítico integra diferentes perspectivas analíticas porque supone que la universidad es una organización compleja. La complejidad de esa organización se expresa en: a) la multiplicidad de bienes que produce, que denotan la variedad de sus fines organizacionales y de su papel en la sociedad y en la economía, b) el proceso decisorio en el cual, debido al estatus particular que le brinda la autonomía académica e institucional, intervienen múltiples actores, dentro y fuera de la organización, cada uno de los cuales detenta un peso diferente en función de la estructura interna del gobierno y de acuerdo con el grado de coordinación ejercido por el Estado o el mercado, c) la variedad y especificidad de los mecanismos de coordinación para la producción económica del servicio educativo universitario, y d) la diferenciación institucional y diversificación de programas a partir de los cuales se ofrece una gran variedad de títulos de grado y posgrado en diversos campos disciplinarios (García de Fanelli, 2005).

Desde una perspectiva institucional se analiza la capacidad del campo universitario para atender las demandas internas y externas a la organización (Acosta Silva, 2014), esto es, la dimensión política del cambio. La atención se focaliza en los cambios en las reglas del desempeño político institucional que provocan ajustes o transformaciones en los patrones de organización preexistentes. Esta corriente cobra mayor sentido si se acepta que el comportamiento de las universidades "es función de la interacción entre los objetivos institucionales, el contexto de mercado dentro del cual opera y las restricciones en términos de regulación a las cuales están sujetas" (García de Fanelli, 2005: 32).

Para García de Fanelli, el cambio en la universidad pocas veces es producto de fuerzas externas que intentan modificar los núcleos que estructuran el funcionamiento de la universidad (García de Fanelli,
2005). Desde esta mirada, la universidad admite dos dimensiones de cambio: la dimensión políticonormativa y la dimensión cultural vinculada a la modificación del núcleo de poder de las estructuras que organizan la jerarquía de sus actividades.

Para la perspectiva de la economía de la innovación, el cambio institucional no se evalúa a través de criterios basados en la eficiencia estática distributiva, sino en cómo promueve el cambio tecnológico y estructural. El abordaje no es ni macro ni micro sino más bien mesoeconómico (Mazzucato, 2016). Para la perspectiva mesoeconómica, la unidad de análisis no es un actor sino la red territorial. Esta red está formada por diversos actores: consumidores, subcontratistas, sistemas de infraestructura, proveedores, competencias o funciones, y las conexiones o relaciones entre ellos. $\mathrm{El}$ argumento es que las competencias que generan innovación son parte de una actividad colectiva que tiene lugar a través de una red de actores y de sus conexiones o relaciones (Mazzucato, 2016).

En vínculo con estas perspectivas, se suman los aportes que conciben la ausencia de un enfoque explícito hacia la innovación social y vinculación tecnológica con eje en el investigador como agente de cambio del sistema (Trippl y Tödtling, 2007). Para superar esto, estas corrientes proponen considerar a la universidad - en tanto espacio de desarrollo del investigador - $\mathrm{y}$ al investigador social como un agente de cambio activo en los modelos de desarrollo local.

Los sistemas de innovación se definen como la "red de instituciones del sector público y privado cuyas actividades e interacciones inician, importan, modifican o difunden nuevas tecnologías" (Mazzucato, 2016) o los "elementos y relaciones que interactúan en la producción, difusión y uso de conocimiento nuevo y económicamente útil” (Lundvall, 1992: 2).

La perspectiva de la gobernanza urbana colabora en la comprensión de las transformaciones territoriales. Los gobiernos locales han ido desarrollando nuevos roles, que han logrado una mejor adaptación 
a las exigencias del nuevo entorno que se caracteriza por un sistema que funciona bajo lógicas menos jerárquicas, de mayor conexión horizontal, en un entorno en el que se debe asumir que hay que combinar capacidades de decisión conjunta con las diferentes esferas de gobierno y con diferentes grados de fragmentación en elementos como la regulación o el suministro concreto de los servicios necesarios para la población (Subirats, 2016).

Esta emergencia de los gobiernos locales obliga a considerar la relación global-local, "ya que lo local aporta a lo global elementos como identidad, territorio y pertenencia, dentro de un sistema más abstracto, virtual y efímero como es la globalización" (Marx, 2008: 27).

Finalmente, en la indagación sobre la participación de la universidad en el territorio subyace el concepto de desarrollo local. Una definición amplia e integral es ofrecida por Coraggio (2003): "el desarrollo local implica la expansión de las capacidades, habilidades, y destrezas productivas, relacionales, comunicacionales, de la iniciativa y creatividad de todos los miembros de la sociedad local, organizados y capaces de regular sus inevitables conflictos de intereses $[\ldots]$ pero compartiendo un proyecto de sociedad más democrática, igualitaria, integradora de todos. Se trata de un desarrollo integral, socioeconómico, político y cultural".

La premisa general que orienta este trabajo plantea que durante las últimas décadas las políticas públicas han promovido desde un punto de vista jurídico, institucional y financiero la asociación regional. Las políticas públicas y universitarias han tendido a promover roles de mayor imbricación territorial. Sin embargo, los resultados de las iniciativas territoriales no son completamente visibles en términos de una performance local o regional. La región metropolitana sur evidencia que si bien se trata de una problemática instalada y reconocida en la agenda universitaria - desde la normatividad e institucionalidad - aún presenta resultados dispersos y heterogéneos.

\section{Apartado metodológico}

Del universo, compuesto por la Ciudad Autónoma de Buenos Aires y 43 partidos (INDEC, 2010) que conforman la Región Metropolitana de Buenos Aires, se seleccionó la Región Metropolitana de Buenos Aires. Esta región, comúnmente denominada Conurbano Bonaerense, a su vez se organiza en tres subregiones: norte, sur y oeste. El análisis se limita a la región metropolitana sur y dentro de ésta al sistema de educación universitario de gestión pública.

El sistema argentino de educación universitaria está conformado actualmente por 131 instituciones educativas. De éste total, 111 son universidades y 20 institutos universitarios. Se distinguen a su vez dos sectores de gestión: la gestión estatal y la gestión privada. La gestión estatal administra un total de 66 instituciones universitarias: 61 universidades y 5 institutos universitarios. La gestión privada administra un total de 63 instituciones: 49 universidades y 14 institutos universitarios (SPU, 2016).

Una de las regiones con mayor concentración institucional es precisamente la región metropolitana de Buenos Aires, donde se reúne más de la mitad de la oferta universitaria en relación con el total observado a nivel nacional (González, 2013). Desde una perspectiva federal, cada una de las 24 jurisdicciones argentinas tiene una universidad nacional, con excepción de Buenos Aires, donde el crecimiento cuantitativo ha sido mayor, dando lugar a un proceso de municipalización de la universidad pública (González, 2013).

De las tres regiones citadas (sur, norte y oeste) la región metropolitana sur tomada individualmente se caracteriza por una mayor concentración institucional. Esta región está compuesta por nueve distritos o gobiernos municipales: Avellaneda, Quilmes, Berazategui, Florencio Varela, Lanús, Lomas de Zamora, Almirante Brown, Esteban Echeverría, Ezeiza. En dicha región funcionan ocho universidades públicas: Universidad Nacional de Avellaneda (2007), Universidad Nacional de Quilmes (1989), Universidad 
Nacional Jauretche (2009), Universidad Nacional de Lanús (1995), Universidad Nacional de Lomas de Zamora (1972), Universidad de Ezeiza y la Universidad Nacional de Almirante Brown creada en 2015 (SPU, 2016); también, la Facultad Regional Avellaneda de la Universidad Tecnológica Nacional (UT NFRA) (SPU, 2016). Estas universidades que además de ser públicas dependen financieramente del Estado nacional, configuran la unidad de análisis del estudio dentro del universo más amplio constituido por el sistema argentino de educación universitaria. A partir de esta selección se escogió una muestra intencional representativa de la población objetivo (el subsistema universitario de la región sur). Es decir, se recoge una muestra no probabilística compuesta por un conjunto de universidades seleccionadas en función de su accesibilidad.

Por su parte, las regiones norte y oeste tienen diez universidades nacionales, que no forman parte de este análisis y sólo se mencionan para contextualizar la selección. En la región metropolitana ubicada al norte de la Ciudad Autónoma de Buenos Aires funcionan la Universidad Nacional de General San Martín (UNSAM) (1992), la Universidad Nacional de General Sarmiento (UNGS) (1995), la Universidad Nacional Tres de Febrero (1995), la Universidad Nacional de Luján, y la Universidad Nacional de Hurlingham (2015). A ello se suman la Facultad Regional Pacheco de la UTN. Mientras que en la región metropolitana oeste están las universidades nacionales de Moreno (2009), Oeste en Merlo, creada en 2009, La Matanza (1989) y José C. Paz (2009).

Otro rasgo relevante de la región metropolitana sur lo constituye su cantidad de habitantes. Revela una cifra superior en relación con las otras dos subregiones. Para 2010 los nueve distritos ${ }^{1}$ suman un total de: 3768994 habitantes. Mientras que para el mismo periodo, la región oeste (compuesta por siete partidos) registra un total de 3760060 habitantes, y la región norte (8 distritos) con 2380661 habitantes (INDEG, 2010).

Estas particularidades de la región metropolitana permiten explorar con mayor riqueza los atributos territoriales que se pretende indagar.

$\mathrm{El}$ análisis integra datos de fuentes primarias y secundarias (documentales, normativas y estadísticas). Como se indicó previamente, la selección del caso hace uso de una técnica de muestreo no probabilístico en función de la accesibilidad a los datos. Este estudio buscó mostrar de qué manera ocurre la vinculación científico-tecnológica de la universidad con su territorio, analizando cómo es observada por sus actores relevantes, sin descuidar, en esta intención, la actuación de la propia universidad en dicha vinculación. Para explorar la actuación de la universidad, el análisis utiliza fuentes documentales (jurídico-normativas) objetivadas en los diseños institucionales. Éstas se integran con el testimonio de algunos secretarios o subsecretarios a cargo de las áreas de vinculación científica de las universidades nacionales donde se accedió en la indagación de fuentes primarias. En este caso, se examinan los propósitos de las universidades cristalizados en sus normas. No se aborda el campo de tensiones vinculado a los intereses de los actores, sus estrategias y prácticas al interior de la organización universitaria. Es decir, excede a los intereses del estudio analizar el modo en que se construye dicha institucionalidad. El abordaje propuesto sólo observa la intención plasmada en sus normas institucionales, en el entendido que la universidad es autónoma y su funcionamiento se rige $-\mathrm{y}$ decide modos de vinculación territorial- a partir de las reglas que ella misma se dicta y emanan de su gobierno (co-gobierno), donde los claustros (profesores, graduados y alumnos) están representados y participan de su construcción. Desde

\footnotetext{
${ }^{1}$ Cabe aclarar que las diversas referencias a distrito, partido o municipio en la Argentina se aplican como términos equivalentes y expresan ámbitos de gobierno local.
} 
este punto de vista, el análisis se plantea desde una mirada institucional que no examina a la organización y los modos en que se gestan los cambios institucionales en su interior. Se trata de mostrar la misión objetiva de las universidades seleccionadas en su entorno próximo. Esta misión se hace evidente y accesible desde fuentes documentales (estatutos, proyectos institucionales). Por este motivo, sumado a las limitaciones de tiempo y recursos involucrados en este estudio, el mayor peso de los testimonios no está puesto en las "voces" de los actores académicos - representados en el gobierno colegiado de la universidad pública - sino en la perspectiva de los actores externos, que por otro lado no tienen institucionalizados sus modos de vinculación con la universidad. Es decir, el único modo de acceder a sus intenciones territoriales es a través de la indagación de fuentes primarias.

Para el análisis de los actores externos a la universidad se centró la atención en los funcionarios políticos de las comunidades locales. Es decir, en los gobiernos provinciales y municipales y dentro de éstos en los sectores con mayores chances de generar oportunidades con la universidad: las áreas productivas. Para ello, se incorporan datos provenientes de entrevistas a actores claves de los gobiernos locales. La decisión de incorporar la palabra de estos actores se toma a partir de constatar la carencia de información institucional en las instancias de gestión pública subnacionales. En ninguno de los casos examinados se encontraron fuentes secundarias que pudieran dar cuenta de la intención oficial de los gobiernos locales para su vinculación con la universidad. En este sentido, la indagación de fuentes primarias abrió el campo de análisis y permitió echar luz sobre los modos en que se posicionan los gobiernos locales en su relación con la universidad. Para ello se recuperó un instrumento de indagación semiestructurado de un plan de entrevistas realizadas por quienes escriben, en el marco de un proyecto más general financiado por la Secretaria de Políticas Universitarias de la Argentina en
2016. Se colectaron datos en aquellos distritos donde el acceso fue permitido. Las posibilidades de acceso al trabajo de campo condicionaron la definición de la muestra. Los municipios donde se recolectaron datos primarios son cuatro: Avellaneda, Quilmes, Lomas de Zamora y Berazategui. Se entrevistó a cuatro subsecretarios de Desarrollo Económico o de la Producción, según el caso, de cada uno de estos municipios. Es decir, cuatro sobre nueve (4/9) distritos que configuran el total. El diseño del instrumento de recolección se basó en una guía de preguntas con dimensiones políticas, académicas y sobre vinculación tecnológica. Como se indicó previamente, la muestra es de carácter intencional no probabilística. Es decir, los resultados no pueden generalizarse al total de los distritos. Cada uno de los municipios se cuenta como una unidad de análisis en sí misma en función de sus diferentes autoridades jurisdiccionales y las regulaciones jurídico-normativas propias.

\section{El sistema universitario argentino}

El campo universitario en Argentina está bajo la jurisdicción del gobierno nacional. Mientras que los niveles de educación elemental y media así como la educación superior no universitaria está a cargo de los niveles subnacionales (provincias y municipios). El sector de educación superior no universitaria está compuesto por más de dos mil instituciones destinadas a la formación de docentes y de técnicos especializados en diversas áreas profesionales (García de Fanelli, 2012).

Históricamente el sector público ha concentrado el $80 \%$ del total de alumnos universitarios (SPU, 2016) por lo que es posible afirmar que el sistema argentino es básicamente estatal, aun cuando es levemente mayor al número de instituciones privadas (Del Bello, 2012).

Si bien Argentina es un país federal compuesto por 23 jurisdicciones y la Ciudad Autónoma de Buenos Aires, las universidades públicas son nacionales y no estaduales o provinciales. Comúnmente, en los 
países con organización federal, las universidades públicas están en jurisdicción de los estados provinciales (Alemania, Canadá, Estados Unidos, Brasil).

La universidad en Argentina se caracteriza por el acceso libre e irrestricto y esta particularidad la distingue de las universidades de la región y también a nivel internacional, aunque este atributo ha sido objeto de debates. Los sostenidos problemas de eficiencia interna de la universidad y la creciente dificultad para garantizar la graduación de una porción amplia de ingresantes han llevado a cuestionar el tipo de selectividad. Por un lado, desde un grupo de trabajos se afirma que la mayor apertura de la universidad garantiza en sí misma la inclusión educativa y la oportunidad de movilidad social ascendente. Desde la perspectiva de acceso irrestricto, se concibe a la apertura del sistema universitario como componente que sustancia la democratización de la educación superior. Mientras que desde otros grupos de trabajos se argumenta que la universidad debe realizar una mayor interpelación hacia sus prácticas educativas y territoriales en función de los débiles resultados en cuanto a la graduación e incidencia social, en términos de sistema (Fernandez Lamarra, 2015; González y Claverie, 2017). Esta concepción promueve un mayor involucramiento de la universidad, dado que el acceso irrestricto no garantiza en sí mismo el éxito del trayecto educativo, debido fundamentalmente a la segmentación de la demanda educativa y los diferenciales puntos de partida de los estudiantes. La equidad requiere además estrategias concretas de articulación entre la universidad y su entorno próximo, que desde un punto de vista sistémico apunten a sustanciar la democratización de la educación superior.

El debate sobre las tensiones entre acceso, calidad y equidad "aún representa un problema central a ser resuelto en el país así como en la mayoría de los países de América Latina, especialmente afectando grupos socialmente desfavorecidos" (Rama, 2006), tanto "por su condición socioeconómica como por otros factores asociados, tales como geográficos, étnico-raciales, de género y/o físicos" (Fernández Lamarra, 2015).

Los estudios de grado en las universidades nacionales son gratuitos desde la ley 13.031 de 1947 sancionada en el primer gobierno peronista, con la excepción de los periodos dictatoriales posteriores (1966/1973 y 1976/1983). La Ley de Educación Superior 24.521 asegura el acceso libre pero deja librada a las universidades la decisión de arancelar o no los estudios de posgrado y las actividades del área denominada extensión universitaria. ${ }^{2}$

Otro aspecto tradicionalmente distintivo es la capacidad institucional implicada por la autonomía universitaria lograda en la Reforma de 1918. Allí se logró enfrentar a una institución elitista y cerrada. Se abrió el campo al cogobierno en la universidad (gobierno de docentes, graduados y estudiantes), eliminaron la presencia obligada de lo religioso, reivindicaron lo científico como el eje central al que la universidad debe ceñirse, e instaron a la libertad de cátedra (Follari, 2015; Buchbinder, 2005).

La Reforma de 1918 cambió fuertemente la condición de la universidad pública, "empezando a abrirla a nuevos sectores, y reivindicó la autonomía como central a los fines de garantizar libertad política por la vía del autogobierno universitario, así como la libertad de cátedra, en cuanto a poder ejercitar con libertad el pensamiento al margen de cuál fuera la posición del gobierno de turno" (Follari, 2015: 23). Desde entonces y bajo regímenes democráticos, el valor y defensa de esta autonomía ha sido fuente de poder e influencia para la universidad.

También ejerce un poder elevado a partir de la autoridad que le confiere la producción de

\footnotetext{
${ }^{2}$ Diversas universidades públicas ofrecen cursos y carreras de formación aranceladas que constituyen a la vez una fuente de ingresos propia para destinar a becas estudiantiles, entre otras.
} 
conocimiento especializado y socialmente relevante. Esta capacidad de intervención social convierte a la universidad en un agente potente a nivel local. $\mathrm{Al}$ respecto, el secretario de vinculación tecnológica de una universidad pública señala en entrevista: "la mirada del sector universitario público en la Argentina es de un campo poderoso. En la actualidad es admisible pensar al sistema político argentino como un modelo multinivel con cuatro esferas de poder: el nivel nacional, el provincial, el municipal y - por el peso de su influencia y capacidad institucional- el nivel universitario" (noviembre de 2016).

En Argentina, la universidad tiene tres objetivos explícitos: la formación de profesionales para el mercado de trabajo (gobierno, empresas, sector académico) (enseñanza); la formación de científicos para la producción y transmisión del conocimiento en las ciencias y la producción de nuevo conocimiento científico (investigación), y la producción de servicios de asistencia técnica, social y cultural a la comunidad (extensión).

A las tradicionales funciones de enseñanza, investigación y extensión universitaria (para aquellos que por diferentes motivos no acceden a la universidad) se sumó entre los años ochenta y noventa una cuarta función: la de vinculación y transferencia tecnológica. La mayoría de las universidades nacionales redefinieron sus estructuras organizativas para incorporar esta cuarta función, y sólo algunas pocas la sumaron explícitamente a sus estatutos. Se comenzó a ponderar qué es relevante y qué no lo es, considerando además que la productividad tecnológica puede aportar a la universidad recursos financieros externos vía patentes y/o invenciones.

Como se indicó previamente, la región metropolitana sur presenta una cantidad superlativa de instituciones universitarias de gestión pública en comparación con las regiones norte y oeste, tomadas individualmente. Además, caracteriza a la región el diseño inclusivo de las universidades, instituidas bajo modelos organizacionales matriciales, con departamentos en vez de facultades, y pensadas como enclaves territoriales para estimular la permanencia y graduación del estudiante así como enlaces con la comunidad de origen.

La capacidad para movilizar recursos está estrechamente vinculada a la puesta en marcha de sus planes de acción estratégicos y del peso que el gobierno de cada universidad otorgue a cada una de las áreas involucradas en su funcionamiento. Esto producirá, a su vez, una específica distribución de recursos físicos y humanos destinados al cumplimiento de sus metas. Desde este punto de vista, el análisis dio cuenta de las actividades previstas para las funciones de docencia, investigación, extensión universitaria y vinculación tecnológica en las ocho universidades de la región sur, aunque la participación de cada una éstas en el territorio evidencia una cuestión de grado.

Un primer grupo de universidades: Ezeiza, Almirante Brown y Lomas de Zamora, dedican mayor tiempo y organización a la oferta académica con una incidencia menor en la investigación, extensión y transferencia científica, visible en la debilidad programática de dichas áreas. Otra característica de la estructura académica en este primer grupo es la concentración de la oferta académica en una sola disciplina y dentro de ésta en un área: las ciencias sociales (Universidad de Lomas de Zamora) y la aeronáutica (Ezeiza). El área de investigación de la universidad de Ezeiza presenta seis líneas de investigación en temas que van desde el medio ambiente hasta la logística del transporte en sus diferentes modalidades. Al área de extensión se suma un "Club de emprendedores", en los que se subsume la representación de actividades para la transferencia científica. En Lomas de Zamora la oferta académica está concentrada en las ciencias sociales; no hay diversificación en otras áreas. Si bien registra áreas de investigación y de vinculación tecnológica, se trata de iniciativas asociadas a las políticas universitarias emanadas por el gobierno nacional a través del programa denominado Incentivos, orientado a apoyar 
la contratación de investigadores a tiempo completo. En el caso de Almirante Brown, se observa que inició en 2016 el dictado de tres carreras de pregrado (tecnicaturas): Gestión de las Organizaciones, Logística y Transporte, y Automatización y Control, tal como refleja su sitio web.

A diferencia de este primer grupo, las universidades de Lanús, Avellaneda, Quilmes, Jauretche y UTN FRA ofrecen carreras distribuidas entre las ciencias básicas y aplicadas, de alta diversificación. Esto es acompañado por una mayor dedicación a la fijación de iniciativas de investigación, extensión y vinculación tecnológica. Estas decisiones se visibilizan en sus agendas de actuación articulando políticas con actores municipales (convenios y acuerdos de cooperación), con actores internacionales (convenios de intercambio, en donde se estimula el trabajo comunitario) y con otros actores del campo universitario y de la educación preparatoria o preuniversitaria. En relación con este último punto, se destacan las escuelas públicas de nivel medio fundadas por Quilmes y Avellaneda, así como otros planes de educación para adultos. Específicamente, la Universidad Nacional de Quilmes presenta una agenda de actuación tecnológica distintiva en la región, en función de su asociación con empresas y la participación en sociedades de base tecnológica. Por esta razón, puede resultar un modelo regional influyente y ya maduro.

La diversificación en la oferta académica facilita una mayor amplitud en la agenda temática de la investigación, así como también en las iniciativas de extensión universitaria. Aunque, como se indicó, el peso de las diversas áreas es mayor o menor según la institución (véase tabla 2). A continuación se examinan los recursos institucionales con los que cuentan las universidades públicas para movilizar sus actividades. Se toma como referencia la estructura jurídica normativa del sistema universitario en su conjunto. A partir de éste se hace referencia específica al caso seleccionado.

\section{Capacidades del sistema universitario}

La configuración de capacidades al interior de las universidades encuentra un antecedente en términos de incidencia para el desarrollo local en la tradición de regionalización universitaria. El Plan Taquini planteó que cada región tuviera una universidad para atender sus demandas particulares. Se puso en marcha en 1968 con la creación de la Universidad Nacional de Río Cuarto (1971) y la del Comahue (1971). En 1972 se crean la Universidad Nacional de Salta, la Universidad Nacional de Catamarca, Lomas de Zamora y Luján. En 1973 crea otras seis universidades nacionales y nacionaliza la Universidad de Jujuy. En 1974 crea la Universidad Nacional del Centro de la Provincia de Buenos Aires, y en 1975 la Universidad Nacional de Mar del Plata. El sistema universitario suma 15 instituciones nacionales, con un total de 25 universidades públicas para 1975.

Posteriormente, la vigente Ley de Educación Superior 24.521 recuperó esta tradición creando siete consejos de Planificación Regional, nucleando a las diferentes regiones: Norte, Sur, Centro Este, Centro Oeste, Metropolitana y Bonaerense. Si bien se instituyen como espacios de concertación regional, algunos trabajos (González, 2013; Taquini, 2014) dan cuenta del protagonismo que asumen las universidades nacionales en estos espacios, mostrando que el interés de los actores por la arena política brinda resultados positivos en la dinámica local.

A su vez, entre 2003 y 2015, el Estado ubicó a las universidades nacionales como "consultoras preferenciales" (Decreto 204/2004) del Estado Nacional, dado que "constituyen entes de reconocido prestigio profesional en cada una de sus áreas, resultando por ello un calificado recurso para abordar las tareas de asesoramiento que el Estado Nacional requiere". Esta política se orientó a depositar en las universidades la labor de asesoría científica y tecnológica desarrollada en forma primaria por think tanks privados, desde los años noventa. Con todo, los atributos 
de la universidad en términos de capacidades institucionales pueden expresarse en cuatro aspectos: legislación, capacidad del presupuesto universitario, recursos humanos y competencias, e iniciativas de la organización y coordinación territorial.

\section{Legislación}

Esta dimensión hace referencia al marco normativo que habilita reglas formales de actuación en un esquema multinivel. Como se señaló previamente, dado que las universidades públicas son financiadas en un porcentaje cercano al $90 \%$ por el Tesoro Nacional y son responsables ante el gobierno nacional (y no ante las provincias o distritos, como ocurre en otros países federales) no hay reglas formales locales que actúen en contrario a la legislación federal. Sin embargo, sí existen otras reglas de juego de carácter informal, que habilitan las prácticas y pautas culturales entre las universidades y otros actores del territorio, pero ello se profundizará más adelante.

Para el análisis jurídico normativo es posible identificar una mayor apertura de la universidad hacia la vinculación territorial desde los años ochenta. En 1981 se promulga la Ley 22.426 de Transferencia Tecnológica y en 1990 la Ley 23.877 de Promoción y Fomento de la Innovación Tecnológica. Esta última ley establece que las universidades quedan facultadas para establecer unidades de vinculación con el propósito de disponer de una estructura jurídica para agilizar el tratamiento con el sector privado en su región.

En 1996 se crea el Fondo Tecnológico Argentino (FONTAR) (Decreto 1660/96) como instrumento para la articulación de universidades y demandas productivas. Este objetivo tiene mayor alcance e integración con la creación de la Agencia Nacional de Promoción Científica y Tecnológica (AGENCIA) en el mismo año, sumado al diseño del Gabinete Científico Tecnológico (GACTEC) en el ámbito de la Jefatura de Gabinete de Ministros, como órgano de coordinación interministerial.

La política tecnológica de los años noventa se caracteriza por el avance de reestructuraciones institucionales que tuvieron como norte la necesidad de orientar la investigación y el desarrollo hacia las necesidades de la industria (Albornoz, 2007). Desde entonces, las universidades nacionales comienzan a instituir estructuras destinadas a favorecer la transferencia de conocimiento y la prestación de servicios al sector privado. ${ }^{3}$ Sin embargo, la política económica de la época, centrada en la apertura de la economía y la estabilidad macroeconómica, conspiraron contra la trayectoria tecnológica de las empresas argentinas y restaron interés a la capacidad de producir localmente conocimientos científicos y tecnológicos relevantes. Es decir, tempranamente se observa que el sector privado no acompañó con el previsto rol demandante estos movimientos (Albornoz, 2007).

Desde 2003, los signos de recuperación que se podían advertir a nivel nacional no sustanciaron un desarrollo potente en las regiones. Asimismo, la cadena de actores productivos pequeños y medianos que las universidades pueden tener a su alcance no tiene capacidad de acceso al mercado externo y, en caso de tenerlo, acceden con escasa competitividad comercial, siendo superados por las economías de la región u otras del primer mundo, como es el caso de China.

Al respecto, el subsecretario de Producción del partido de Quilmes en la provincia de Buenos Aires, señala en entrevista:

En la mayoría de los sectores, yo recorro todo y ya visite 600 empresas, la situación está muy difícil. El

\footnotetext{
${ }^{3}$ En particular, en la Universidad de Buenos Aires (UBA) la relación económica con el sector productivo comienza formalmente en 1987 con la creación de la Dirección de Convenios y Transferencias. A partir de allí, el Consejo Superior de la UBA dictaminó una serie de resoluciones orientadas a flexibilizar la regulación vigente a los fines de que permitieran entablar esta nueva forma de relación económica.
} 
empresario argentino se reinventa, inventa soluciones donde sólo tenemos problemas, la creatividad que tenemos es infernal, eso es lo que yo rescato de nosotros como empresarios, la capacidad de poder encontrar negocios en donde no se supone que hubiere nada es fantástica. Yo veo mucha creatividad y muchas ganas de no querer cerrar. Lo bueno de eso es que cuando vos te acercás con herramientas concretas, le da la posibilidad de reinventarse. El problema es que esta reinversión lleva tiempo, yo puedo tener la ventaja competitiva de llegar como estado a las 2200 PYMES pero el tiempo para la reinversión es un tiempo de un año o dos años. Es un proceso complejo, eso va a llevar un año o dos años más como mínimo, sosteniendo esta coyuntura económica y este programa de apertura de mercado, y todas las cuestiones que estamos viviendo (marzo de 2016).

Esta opinión es apoyada por el subsecretario de Producción del territorio de Lomas de Zamora, provincia de Buenos Aires, cuando señala:

La preocupación de hoy es el grado en el que se afecta el empleo. Tenemos una caída interanual de exportaciones y del comercio del 52\%, y un diagnóstico negativo en todo el Conurbano. Esta tendencia declinante comienza a manifestarse desde 2014. Entre 2003 y 2014 el sector se desarrollo de un modo altamente competitivo. Se trabaja y se trabajó articuladamente con el nivel nacional y provincial desarrollando ronda de compradores. Pero el problema clave es el de la competitividad (abril de 2016).

Desde este punto de vista, la evolución positiva a nivel macroeconómico no tiene un correlato en la competitividad territorial. En este periodo se sancionó la Ley 26.075 de Financiamiento Educativo. A través de esta ley, el gobierno nacional y los gobiernos provinciales se comprometieron a incrementar la inversión en educación, ciencia y tecnología hasta alcanzar la meta del 6\% del PBI en el año 2010 (Broto, 2012).
Bajo un nuevo contexto, la gestión de la innovación y transferencia de tecnología se convierte en uno de los ejes que atraviesa la discusión universitaria. Los aspectos normativos de la política institucional quedan librados a la orientación autonómica de las universidades públicas y a sus planes de desarrollo organizacional. Estas reglas no pueden generalizarse al conjunto de universidades sino que forman parte de las reglas estatutarias del gobierno de cada universidad.

\section{Capacidad del presupuesto universitario}

El financiamiento total del sistema universitario se expresa básicamente en los aportes que el Estado nacional destina a las universidades nacionales, y en el caso del sector universitario privado, en el pago de aranceles por parte de los estudiantes. El financiamiento estatal se materializa en las asignaciones a través de la ley de presupuesto anual de la administración pública nacional. De acuerdo con García de Fanelli (2011: 45), "para 2008 esta tendencia se mantenía en una relación de $87 \%$ a $13 \%$ concentrando la distribución de la ejecución presupuestaria en el Tesoro Nacional (87\%)".

A partir del Decreto 2329/94, cada institución universitaria recibe una subvención global, que en términos de imputación presupuestaria se desagrega en tres funciones: educación, salud y ciencia y tecnología. Entre ellas, la principal es la función educación, que representa alrededor del 90\% del presupuesto total. Una vez asignada la subvención global, las instituciones elaboran y aprueban su propio presupuesto a través de sus órganos colegiados de gobierno (Del Bello, 2012). Para el sector de ciencia y tecnología, el presupuesto universitario se determina, como en todo organismo público, con base en el gasto del año anterior. Esto permite reproducir la estructura existente, pero tiende a la vez a mantener el status quo, ya que no atiende nuevas demandas ni contempla mejoras en la calidad o los resultados. En este marco, las universidades nacionales afectan mayores recursos para ciencia y tecnología, transfiriendo 
fondos de la función educación a las funciones de investigación y desarrollo científico.

En 1996, la Secretaría de Políticas Universitarias diseñó el Modelo de Asignación Presupuestaria. Esta metodología tiene sus bases en los aportes que, desde 1994, realizaron las universidades en distintos ámbitos, particularmente en el Consejo Interuniversitario Nacional. Este modelo reparte el $100 \%$ del incremento presupuestario en tres categorías: $45 \%$ para el "Bloque Economía de Escala, Complejidad de la Oferta Académica y Actividad Académica"; 50\% para el "Bloque Presupuesto Normativo", y 5\% para el "Bloque Ciencia y Técnica".

Sin embargo, para 2010 la ejecución presupuestaria global clasificada por fuente de financiamiento muestra que, para las universidades de la región en análisis, el gasto ejecutado corresponde casi totalmente a las fuentes del Tesoro Nacional. Es muy bajo el porcentaje ejecutado a partir de recursos genuinos que pueda generar la universidad (tabla 1). Las otras fuentes de financiamiento de las universidades nacionales se agrupan en la categoría de "recursos propios". Éstos comprenden "ingresos por aranceles de los estudios de posgrado (el nivel de grado en las universidades nacionales es gratuito) y venta de servicios técnicos, consultorías, capacitación, etcétera, y otros fondos vinculados con ingresos generados por las propias universidades a partir de su relación con el sector productivo" (García de Fanelli, 2011: 21).

En 2016, el total presupuestado por el Tesoro Nacional alcanza a 49815 millones de pesos, equivalentes a 4700 millones de dólares (el presupuesto de 2016 estimaba un valor de 10.60 pesos por dólar). Este presupuesto abarca tres rubros: Salud, Educación y Cultura y Ciencia y Técnica. El cuadro 1 presenta la distribución de estos fondos presupuestarios entre las universidades de los distritos seleccionados para este estudio.

El modo de ejecutar los presupuestos en cada institución de acuerdo con sus objetivos es lo que permite organizar los cuerpos de investigación y desarrollo así como de la vinculación con redes de ciencia y tecnología a nivel nacional e internacional. Esto se analizará a continuación.

Tabla 1. Ejecución del gasto por fuente de financiamiento en universidades seleccionadas de la región metropolitana sur, 2010

\begin{tabular}{|l|c|c|c|c|c|}
\hline \multicolumn{1}{|c|}{$\begin{array}{c}\text { Fuentes de financiamiento } \\
\text { Nacional }\end{array}$} & Total & Tesoro nacional & Recursos propios & $\begin{array}{c}\text { Remante ejercicios } \\
\text { anteriores }\end{array}$ & Otras fuentes \\
\hline Quilmes & 107504952 & 84524136 & 10307687 & 10981388 & 1691741 \\
\hline Lomas de Zamora & 210429371 & 181698209 & 12807544 & 15923618 & 0 \\
\hline Avellaneda4 & 1121301 & 1121301 & 0 & 0 & 0 \\
\hline Tecnológica Nacional & 1343589212 & 841914193 & 488918931 & 12756088 & 0 \\
\hline Lanús & 93635123 & 63364026 & 19868911 & 10314562 & 87624 \\
\hline Arturo Jauretche & 741525 & 741525 & 0 & 0 & 0 \\
\hline
\end{tabular}

Fuente: Del Bello (2012). Aclaración: sin registro de las universidades Almirante Brown y Ezeiza, creadas con posterioridad.

\footnotetext{
${ }^{4}$ Para el caso de la Universidad Nacional de Avellaneda cabe considerar que 2010 es su primer año de funcionamiento, sin dictado de clases, que comienza en 2011.
} 


\section{Cuadro 1. Distribución de fondos según cantidad de alumnos y gasto por alumno para universidades seleccionadas de la región sur, 2016}

\begin{tabular}{|l|c|c|c|c|}
\hline \multicolumn{1}{|c|}{$\begin{array}{c}\text { Universidad } \\
\text { Nacional }\end{array}$} & $\begin{array}{c}\text { Presupuesto en educación y } \\
\text { cultura (\$) }\end{array}$ & Alumnos & $\begin{array}{c}\text { Presupuesto por } \\
\text { alumno }\end{array}$ & $\begin{array}{c}\text { Presupuesto por } \\
\text { alumno (USD) }\end{array}$ \\
\hline Quilmes & 442739274 & 24164 & 18322 & 1728 \\
\hline Lomas de Zamora & 713562070 & 37062 & 19253 & 1816 \\
\hline Avellaneda & 167315442 & 4868 & 34369 & 3242 \\
\hline UTN FRA & 114145000 & 2872 & 13832 & 2299 \\
\hline Arturo Jauretche & 205217529 & 8421 & 24369 & 2357 \\
\hline Lanús & 344917716 & 13804 & 24987 & 1467 \\
\hline
\end{tabular}

Fuente: Presupuesto 2016 del Honorable Congreso de la Nación. Aclaración: sin datos para las universidades nacionales de Almirante Brown y Ezeiza, creadas posteriormente.

\section{Recursos humanos y competencias}

Las estructuras académicas de las universidades públicas analizadas reflejan una baja participación de investigadores de tiempo completo. Los cuadros a continuación muestran de qué manera se organizan las universidades de la región metropolitana sur y cómo se distribuyen los escalafones en el campo de investigación. Es notable el caso de la Universidad Nacional de Lomas de Zamora (UNLZ) que tiene el cuerpo de investigadores más importante de la región, pero esto no parece reflejar un mayor nivel de actividades en comparación con la región en examen.

En palabras de un subsecretario de producción del distrito de Lomas de Zamora, Provincia de Buenos Aires: "El municipio no tiene vínculo alguno con la universidad. No realizamos consultas ni tenemos canales de comunicación activo con la universidad. Y la verdad que nos gustaría mucho dado que tenemos diversos problemas de infraestructura y desarrollo. El único vínculo que tenemos con el nivel nacional es con el Poder Ejecutivo, con quien realizamos diversos encuentros o mesas de negocios" (mayo de 2016).

Esta opinión es apoyada por los actores productivos de la región. Al respecto señala un empresario industrial en entrevista: "La universidad no nos convoca para mejorar la productividad del sector o para programar una mesa de negocios para competir con productos que hace años están entrando de Brasil o China. La economía regional no es competitiva porque estos países venden por debajo del costo de producción" (mayo de 2016).

En este sentido, si bien se han creado en la totalidad de universidades examinadas distintas áreas de trasferencia científica, esto no ha sido acompañado de una mayor dedicación de los investigadores a la formación de una agenda de producción científica. 
Tabla 2. Características organizacionales de las universidades nacionales de la región sur, 2013

\begin{tabular}{|c|c|c|c|c|c|c|c|}
\hline Universidad & Creación & Diseño institucional & Tamaño & Estudiantes & Egresados & Disciplinas & Área CyT \\
\hline Avellaneda & 2009 & Departamentos & Pequeña & 4523 & 54 & $\begin{array}{l}\text { Ciencias humanas, } \\
\text { sociales, aplicadas } \\
\text { (ingenierías), } \\
\text { ambientales, } \\
\text { arquitectura y ciencia } \\
\text { de la salud. }\end{array}$ & $\begin{array}{l}\text { Secretaría de } \\
\text { Investigación e } \\
\text { Innovación Socio- } \\
\text { Productiva }\end{array}$ \\
\hline Lomas de Zamora & 1972 & Departamentos & Grande & 34434 & 2515 & $\begin{array}{l}\text { Ciencias humanas, } \\
\text { sociales, ciencias } \\
\text { aplicadas. }\end{array}$ & $\begin{array}{l}\text { Secretaria de } \\
\text { Vinculación } \\
\text { tecnológica }\end{array}$ \\
\hline Quilmes & 1989 & Departamentos & Mediana & 22451 & 839 & $\begin{array}{l}\text { Ciencias humanas, } \\
\text { sociales, ciencias } \\
\text { aplicadas. }\end{array}$ & $\begin{array}{l}\text { Secretaria de } \\
\text { Innovación y } \\
\text { Transferencia de } \\
\text { Tecnología }\end{array}$ \\
\hline UTN FRA * & 1968 & Facultades Regionales & Grande & 2670 & 158 & $\begin{array}{l}\text { Ciencias básicas y } \\
\text { aplicadas. }\end{array}$ & $\begin{array}{l}\text { Secretaria de Ciencia } \\
\text { y Tecnología }\end{array}$ \\
\hline Lanús & 1995 & Departamentos & Grande & 12825 & 491 & $\begin{array}{l}\text { Ciencias humanas, } \\
\text { sociales, aplicadas y } \\
\text { ciencia de la salud. }\end{array}$ & $\begin{array}{l}\text { Departamento } \\
\text { de Desarrollo } \\
\text { Productivo y } \\
\text { Tecnológico }\end{array}$ \\
\hline Almirante Brown & 2015 & Departamentos & Pequeña & 0 & 0 & $\begin{array}{l}\text { Ciencias aplicadas y } \\
\text { ciencia de la salud. }\end{array}$ & - \\
\hline Arturo Jauretche & 2009 & Departamentos & Grande & 7824 & 0 & $\begin{array}{l}\text { Ciencias humanas, } \\
\text { sociales, aplicadas y } \\
\text { ciencia de la salud. }\end{array}$ & $\begin{array}{l}\text { Dirección de } \\
\text { Investigación }\end{array}$ \\
\hline Nacional de Ezeiza & 2015 & Departamentos & Pequeña & 0 & 0 & Ciencias aplicadas & $\begin{array}{l}\text { Departamento } \\
\text { de Desarrollo } \\
\text { Tecnológico }\end{array}$ \\
\hline
\end{tabular}

Fuente: Anuario SPU (2013). * A nivel nacional la Universidad Tecnológica registra 80052 Estudiantes y 4757 egresados

Cuadro 2. Escalafón docente universitario, cargos por dedicación y por universidad, 2013

\begin{tabular}{|l|c|c|c|c|c|}
\hline \multicolumn{1}{|c|}{ Instituciones } & $\begin{array}{c}\text { Total cargos } \\
\text { docentes } \\
\text { universitarios }\end{array}$ & Exclusiva & Semi-exclusiva & Simple & $\begin{array}{c}\text { Otros (Ad Honorem, } \\
\text { Jefe Bedelía, } \\
\text { Contratos) }\end{array}$ \\
\hline Total UUNN & 166810 & 20645 & 31731 & 108264 & 6770 \\
\hline Avellaneda & 451 & 12 & 6 & 116 & 317 \\
\hline Lomas de Zamora & 3632 & 118 & 182 & 3235 & 97 \\
\hline Quilmes & 1021 & 232 & & 462 & 26 \\
\hline UTN FRA & 718 & 23 & 22 & 665 & 6 \\
\hline Jauretche & 612 & 76 & 104 & 39 & 393 \\
\hline Lanús & 844 & 98 & 221 & 289 & 236 \\
\hline
\end{tabular}

Fuente: Anuario SPU (2013). Aclaración: sin registro de las universidades Almirante Brown y Ezeiza, creadas con posterioridad. 


\section{Cuadro 3. Cantidad de cargos con dedicación exclusiva según Universidad. Variación porcentual (2009-2013)}

\begin{tabular}{|c|c|c|c|c|c|c|c|c|c|c|}
\hline \multirow[b]{2}{*}{ Institución } & \multicolumn{5}{|c|}{ Dedicación } & \multicolumn{5}{|c|}{ Variación en \% } \\
\hline & 2009 & 2010 & 2011 & 2012 & 2013 & 2009/2010 & 2010/2011 & $2011 / 2012$ & $2012 / 2013$ & $2009 / 2013$ \\
\hline Total UUNN & 19461 & 19931 & 20355 & 20638 & 20677 & 2.4 & 2.1 & 1.4 & 0.2 & 6.2 \\
\hline Avellaneda & & & & 7 & 12 & & & & 58.3 & \\
\hline Lomas de Zamora & 102 & 112 & 111 & 113 & 118 & 9.8 & -0.9 & 1.8 & 4.4 & 15.7 \\
\hline Quilmes & 454 & 219 & 240 & 283 & 301 & -51.8 & 9.6 & 17.9 & 6.4 & -33.7 \\
\hline UTN FRA & 19 & 20 & 22 & 22 & 23 & 5 & 4.6 & 2 & 1.6 & 13.9 \\
\hline Arturo Jauretche & & & & 48 & 76 & & & & 58.3 & \\
\hline Lanús & 13 & 28 & 40 & 48 & 98 & 115.4 & 42.9 & 20 & 104.2 & 653.8 \\
\hline
\end{tabular}

Fuente: Anuario SPU (2013). Aclaración: sin registro de las universidades Almirante Brown y Ezeiza, creadas con posterioridad.

\section{Iniciativas universitarias}

Para analizar las iniciativas de las universidades de la región metropolitana sur se ha recurrido al tratamiento de sus normas y estatutos universitarios, así como a la organización institucional plasmada en cada sitio web universitario. Contribuyen a ilustrar este apartado algunos testimonios recogidos en entrevista bajo los términos descritos en los criterios metodológicos ya mencionados.

Un primer grupo de universidades nacionales: Avellaneda y Lomas de Zamora, presenta espacios institucionales orientados a satisfacer demandas de innovación. En el caso de la Universidad Nacional de Lomas de Zamora, su área de vinculación tecnológica promueve programas e iniciativas para participar de nuevos modos de coproducción del conocimiento. Esto es, entre actores universitarios y otros externos interesados en articularse. Pero en esta área no es posible detectar canales de comunicación operativos o rutinas establecidas con otros actores privados o públicos. Por su parte, la Universidad Nacional de Avellaneda crea en 2014 la Subsecretaría de Vinculación Tecnológica ${ }^{5}$ a partir de la cual se diseñan instancias formales de intercambio con el sector productivo, se habilita la Unidad de Vinculación Tecnológica de la Universidad y se generan vínculos de trabajo con las dos universidades con mayor desarrollo en esta área y cercanas en el territorio, como son Quilmes y Lanús. También se hizo hincapié en la formulación de proyectos de desarrollo tecnológico y social (PDTS) en interacción con actores importantes de la región, en temáticas tan sustanciales como la economía popular, la gestión inclusiva en Villa Tranquila, Maciel y Dock Sud, conjuntamente con el municipio, la salud ocupacional en las PyMES de la zona o el turismo social. Del mismo modo se impulsaron, dos importantes proyectos, financiados por SPU y el Ministerio Nacional de Ciencia, Tecnología e Innovación Productiva (MINCyT), de articulación entre movilidad urbana, transporte y logística. Desde 2014, la universidad, en

\footnotetext{
${ }^{5}$ Dicha Subsecretaría apenas estuvo en funciones cerca de ocho meses, luego, por cuestiones presupuestarias, se subsumió al área de la Secretaría de Investigación.
} 
estrecha colaboración con la Unión Industrial de Avellaneda, comienza a dictar la licenciatura en Gerencia de Empresas, orientado hacia PyMES. Aún con estas iniciativas, un subsecretario de Producción de Lomas de Zamora, provincia de Buenos Aires, afirma en entrevista: "La universidad no conoce al detalle lo que pasa con la empresa, no está interiorizada. Sumado a que la lógica de funcionamiento de la universidad dista mucho de las lógicas más acuciantes de las empresas que en la mayoría de los casos necesitan soluciones inmediatas" (mayo de 2016).

Esta afirmación es apoyada por el subsecretario de Producción de Avellaneda, provincia de Buenos Aires:

En realidad sería muy interesante que las universidades tuvieran un rol más en conjunto con la Secretaria de Producción y con empresas directamente. Cuando nosotros bajamos la relación a veces entre actividades gremiales y empresarios y universidades, se pierde un poco. Yo sugiero, si pudiéramos coordinar acciones concretas con las universidades. Si yo me juntara con las universidades, puedo ver si lo que pueden estudiar es acorde a las necesidades industriales del distrito. Históricamente, entre las empresas y la universidad hay una desconexión (abril de 2016).

En la Universidad Nacional Arturo Jauretche (UNAJ) se despliega como iniciativa territorial primaria el Centro de Política y Territorio (CPyT). Desde esta área trabaja para afianzar su vinculación con las comunidades de la región metropolitana sur: Florencio Varela, Berazategui, Quilmes y Almirante Brown. A tal fin dispone de unidades de vinculación para el desarrollo de la comunicación a partir de los avances tecnológicos en el área audiovisual, con el fin de ampliar la información y el acceso al conocimiento. El Centro de Política y Territorio se encuentra organizado en unidades y coordinaciones. Cuenta con las unidades de Vinculación cultural, de
Vinculación tecnológica, de Vinculación audiovisual y de Vinculación educativa. Son destacables las acciones de vinculación con los centros de gestión, con el gobierno municipal y organizaciones sociales locales, el desarrollo de actividades culturales en y para la comunidad, y los estudios y la formación política abiertos a toda la comunidad.

Para el caso de la Universidad Nacional de Lanús existe una Secretaria de Ciencia y Tecnología y un Consejo Departamental de Desarrollo Productivo y Tecnológico. Pero esto no evidencia actividades ni convenios con otros actores. Es decir, funcionan "a demanda" de posibles requerimientos y/o problemas que sí surgen de la investigación científica.

La Universidad Nacional de Quilmes (UNQ) plantea diferencias en cuanto a las lógicas que caracterizan a las universidades previamente citadas ya que parece presentar cierto acervo institucional en términos de comunicación y facilitación. Desde el área de "Innovación" la UNQ despliega unidades ejecutoras, Start ups (empresas de base tecnológica), servicios tecnológicos, productos y licencias.

Las unidades ejecutoras son los laboratorios, centros y programas de la UNQ que cuentan con capacidades y equipamiento para el desarrollo y transferencia de conocimientos y tecnologías. Se organizan en seis áreas y disciplinas: Arte y Tecnología (dos unidades), Biotecnología (Ingeniería, Educación y tecnología, Estudios sociales y Tecnología en alimentos). Como resultado de estas acciones, la UNQ forma parte de una diversidad de empresas de base tecnológica.

Uno de los objetivos de la Dirección de Vinculación y Transferencia Tecnológica es asistir a investigadores y desarrolladores en el proceso de formación de empresas de base tecnológica, apoyándolos en la búsqueda de respuestas frente a obstáculos como la carencia de gerentes (managers) capacitados, o el acceso a capital de riesgo y créditos adecuados para nuevos emprendimientos. En cuanto a los servicios tecnológicos, su plataforma institucional ofrece servicios para la industria y servicios para la comunidad académica. 
Finalmente, los productos y licencias de la UNQ forman parte de su actividad de investigación científica y tecnológica. Uno de los objetivos de esta unidad de transferencia es asistir y acompañar a aquellas organizaciones interesadas en mejorar sus tasas de innovación y competitividad a través de la introducción de dichos productos y tecnologías en sus ofertas de bienes y servicios, como así también en sus procesos productivos y estructuras organizacionales.

En los hechos, la UNQ es una de las instituciones de referencia no solo para Quilmes sino también para Berazategui, Lanús, Lomas de Zamora e incluso Florencio Varela. Pero la posibilidad de conectar una red de instituciones más amplia para innovar está más vinculado a aquellos arreglos informales que suceden entre los actores que a espacios formales de concertación política.

\section{Discusión}

\section{La política pública y las políticas territoriales de innovación}

En las últimas décadas es posible observar un giro en el papel del Estado Nacional como actor activo para el cambio tecnológico. Bajo el paradigma de la calidad y la rendición de cuentas impulsado por los gobiernos nacionales, las políticas públicas hacia las universidades han enfatizado nuevas prácticas de innovación científica y transferencia tecnológica, sobre todo en el campo de las universidades públicas, buscando modelar nuevas relaciones entre universidad-sociedad y Estado.

El artículo se orientó a problematizar estos nuevos vínculos entre universidad-sociedad y Estado, entendiendo que ocurren, tal como ha sucedido con anteriores políticas de racionalización y mejora de la universidad, en el marco de un conjunto de cambios de orden global. Se trata de cambios que además se asocian a contextos sociales, políticos y económicos de carácter más general dentro de los cuales se sitúa el cambio universitario.
En particular, los fenómenos que viene experimentando Europa durante los últimos diez años, como mínimo, vinculados a la mayor intromisión de la universidad en la productividad económica. En Europa el discurso de la transferencia de tecnologías y la innovación científica ha introducido a la universidad en una lógica de "utilidad social".

Para los organismos internacionales de vanguardia y las corrientes hegemónicas del capitalismo avanzado esto representa enormes beneficios para la universidad en función de su mayor incidencia en las esferas social y estatal, basándose en su capital cultural y capacidad de innovación.

En cambio, desde otras corrientes más críticas de carácter "contra hegemónico" se considera que esta lógica puede resultar "peligrosa" para la universidad porque lleva a la mirada superficial de lo urgente y evita el planteo profundo de aspectos que se ven sin "utilidad" pero que pueden ser mucho más importantes para abordar los asuntos sociales. Se tecnifica la discusión, pero los aspectos políticos y teóricos más profundos son cada vez menos abordados. Desde este punto de vista, la universidad, al menos en Europa, parece estar quedando a merced de las necesidades que plantea el Estado y el mercado. Esto ha llevado a autores como Boaventura de Sousa Santos (2017) a calificar el momento como una etapa de "fascismo plural", donde el Estado está al servicio de las demandas del mercado. En esta línea, el discurso de la transferencia e innovación sujeta un vínculo inexorable entre universidades al servicio del Estadomercado, en lugar de cuestionarlo, lo cual disciplina un tipo de vínculo específico.

No obstante ello, en Occidente han calado hondo las ideas sobre la transferencia científica y se ha asumido que la universidad puede destinar iniciativas crecientes a satisfacer demandas del mercado. Más aún cuando los organismos internacionales de vanguardia han concentrado un flujo de capitales importante para financiar el desarrollo de tecnologías aplicables. Bajo este discurso, las estructuras que 
organizan las universidades y el papel de los investigadores han tendido a redefinirse. Estos debates, que han comenzado a instalarse en los países más desarrollados, abren la complejidad del tema dando lugar a nuevos modelos de intervención.

Más allá de esto, en Argentina las iniciativas sobre imbricación entre universidad y territorio cada vez con más fuerza se instalan alrededor de la producción de innovación y transferencia de tecnologías. En la actualidad, las universidades conectan, en muchos casos, directamente con organismos internacionales que promueven importantes fuentes de financiamiento para la producción de tecnología transferible. También los gobiernos nacionales y locales tienden a valorar y promover la producción de innovación tecnológica que logre resolver problemas complejos de la esfera social y económica. Es decir, la universidad se piensa como un agente territorial que puede contribuir a mejorar la calidad y dinamismo comunitario. Pero en América Latina aún no se observa un campo fecundo de cuestionamientos sistemáticos a este modelo de innovación en crecimiento.

Antes bien, el Estado viene apoyando políticas de regionalización y regulación con el propósito de acercar a las instituciones públicas a las demandas relevantes de cada región. Se observa así un aumento en la complejidad institucional que, en Argentina, adquiere un momento cumbre en 2007, con la creación del Ministerio Ciencia, Tecnología e Innovación Productiva. ${ }^{6}$

A diferencia de la institución de estructuras y dotación de recursos para la ciencia y la tecnología que caracteriza a los procesos de creación institucional de los noventa, en el cambio de década el énfasis no se pone en el stock de $\mathrm{I}+\mathrm{D}$, sino en la circulación del conocimiento y en su difusión a través de toda la economía. En este proceso, las universidades nacionales aparecen como unidades de cambio distintivas en función de su capacidad para formar y constituir conocimiento especializado para la región. Incluso, durante la última década, pueden aparecer como agentes de gobernanza urbana en la medida que se han instalado en áreas territoriales periféricas a la ciudad capital de Buenos Aires (tal es el caso de la Universidad Arturo Jauretche en el territorio de Florencio Varela). Su creación y capacidad de dinamizar y concentrar la producción de conocimiento aporta una trama de vínculos y esferas de negociación institucional implicadas en las demandas de urbanidad.

Pero el contrapunto central aquí se presenta en las diferentes agendas de actuación entre el Estado, el mercado y las universidades. El gobierno nacional (nivel central) sostiene discursos e inversiones orientados a satisfacer demandas de productividad tecnológica.

Se trata de un movimiento que pocas veces acompañan los gobiernos locales, más comprometidos con la proximidad de los problemas y las presiones por resolver aquellos que son más urgentes. En este escenario, los gobiernos regionales y locales son parte del problema y parte de la solución. Sobre todo cuando por un lado se refuerza la globalización y por la otra se acentúa la significación de la estructura de oportunidades vitales que cada territorio, cada comunidad local, dispone en mayor o menor medida.

En un contexto de pluralidad institucional y gobernanza multinivel las principales políticas dirigidas hacia la política comunitaria son iniciativas desde el punto de vista de la normatividad.

\section{Conclusiones}

El estudio propuesto intentó mostrar cómo opera la universidad en su territorio próximo. Se dió cuenta de la intencionalidad jurídico-normativa e institucional de las políticas públicas para aumentar los

\footnotetext{
${ }^{6}$ Cabe aclarar que diez años después, bajo otra conducción partidaria en el Estado Nacional, el Ministerio de Ciencia, Tecnología e Innovación Productiva descendió al rango de Secretaría, aunque no perdió la complejidad de sus estructuras burocráticas y organizativas, sí redujo la inversión en el área..
} 
vínculos de la universidad con el territorio y mejorar las oportunidades de desarrollo local. Las políticas de regionalización del Plan Taquini se orientaron en este sentido y las regulaciones de los noventa han tendido a estimular la articulación y coordinación del quehacer universitario para proyectar las necesidades de sus actores relevantes, por región. En estas iniciativas la universidad pública ha experimentado diversos modos de vinculación. Sobre todo cuando estas relaciones han tendido, más recientemente, a la búsqueda de "productos" concretos de la ciencia para aportar soluciones a problemas relevantes y socialmente complejos, que en muchos casos requieren respuestas interdisciplinarias.

No obstante, en el análisis de las políticas públicas implementadas en la universidad es común verificar que se asume implícitamente que la sola puesta en marcha de las políticas presupone su éxito, cuando probablemente lo que puede suceder sean modificaciones adaptadas y resignificadas en la estructura de la organización, sin consecuencias para el núcleo duro de funcionamiento de esta última (García de Fanelli, 2005). En este sentido, las políticas de vinculación entre universidad y territorio implementadas en el sector universitario no constituyen una excepción.

El caso seleccionado muestra que más allá de las agendas globales y oficiales que interpelan a las universidades a aumentar la transferencia de tecnologías, las instituciones en el nivel territorial desarrollan agendas de trabajo locales con distintos grados de profundidad. Uno de los modos más fuertes de vínculo entre la universidad y el territorio tiene que ver con la oferta de extensión universitaria hacia la comunidad. En los casos examinados aparece como un valor transversal el servicio a la comunidad local, para aquellos que por distintos motivos no acceden a una carrera universitaria. Desde cursos de actualización hasta asesorías legales, servicios en el campo de la salud y en áreas educativas no universitarias y preuniversitarias, como puede ser el dictado de clases de apoyo para la educación elemental. Un segundo modo, bajo diversos grados de penetración, es el desarrollo de agendas de investigación y transferencia de tecnología. En este sentido se indicó que algunas universidades muestran mayor dinamismo que otras. Siendo el caso de la Universidad Nacional de Quilmes paradigmático por su participación en empresas de base tecnológica de nivel local. Estas diferencias parecen indicar que el desempeño de las universidades no responde a un perfil regional o a un modo relacional que une componentes para el desarrollo de un "sistema" de innovación. Antes bien, sus objetivos están muy vinculados a los compromisos institucionales que cada universidad asume con tres aspectos de su organización: a) sus estudiantes inscritos y previstos, b) la jerarquía de sus proyectos académicos a partir de los cuales se organizan recursos y funciones, y c) el modo en que recibe/ intercepta demandas del entorno. Se concluye que es el interés (y estrategia) de los actores lo que determina la participación en la arena política en la que se desenvuelven.

La función social de la universidad opera en forma latente o implícita desde la enseñanza, mejorando el acervo cultural y brindando oportunidades de movilidad social ascendente por el acceso masivo e irrestricto a carreras universitarias. Pero lo hace en forma explícita a través de las actividades de extensión y vinculación tecnológica. La función de extensión universitaria ha sido consolidada en la Ley 24.521 de Educación Superior al reconocer y reglamentar tres funciones vitales de la universidad: docencia, investigación y extensión. Por un lado, la universidad funciona bajo este contexto legal dentro del cual operan el conjunto de universidades públicas y privadas. Pero por otra parte, tal como se planteó, la universidad pública en Argentina, depende financieramente de las transferencias ejecutadas por el Tesoro Nacional que conduce el gobierno central. Es decir, a partir de los fondos provenientes de la recaudación tributaria aportada por los ciudadanos de la nación. 
Incluso de aquellos ciudadanos en condiciones socioeconómicas de alta vulnerabilidad social que a través del pago de impuestos al consumo contribuyen al funcionamiento de la universidad, aun cuando probablemente jamás accedan o se gradúen en ella.

Por estos motivos, y atento a sus marcos legales, el rol de la universidad en el territorio supone crear circuitos institucionales para la apertura al diálogo con otros actores locales así como también con los perfiles estudiantiles, siendo éstos la "razón de ser" de la universidad. Se trata de crear circuitos de mutua comprensión de las diferentes lógicas de acción entre la universidad, las empresas y gobiernos subnacionales. Desde esta mirada, se trata más de un problema de "ética de la responsabilidad" que de preferencias de actuación de la universidad pública en el desarrollo territorial.

No obstante ello, en la sección de discusión se plantearon posibles limitaciones a esta misión social/ tecnológica de la universidad en el territorio; si este papel resguarda su modelo de gobierno o queda totalmente atado al mercado y la universidad pierde su esfera de "autonomía", algo que ya llevó en Argentina a la Reforma Universitaria de 1918, al proclamar la defensa de la investigación desinteresada y de alta calidad sin dependencias de actores externos.
Finalmente, del análisis se derivan algunos ejes temáticos valiosos para abordar en estudios futuros. Uno de ellos tiene que ver con un tratamiento crítico de la universidad como actor territorial. Esto es, los alcances de pensar a la universidad como actor que aporta al desarrollo productivo y sustentable. ¿La universidad debe subsumirse a esa función? ¿Qué posición debe asumir la universidad pública de cara a los desafíos de la época? ¿Qué posición asumirá la universidad respecto de problemas que ya discute la agenda internacional acerca de temas transversales y globales, como lo es el hábitat sustentable o la producción de energías renovables? ¿Cómo se imbricará la institución universitaria en una red de problemas dentro de los que se encuentra inmersa, producto de la internacionalización del conocimiento? Esto supone un balance crítico de distintos aspectos sociohistóricos, políticos y culturales de la universidad en Argentina.

Otro de los ejes está asociado al modo de inserción de la universidad en diferentes sistemas de innovación, de acuerdo con las demandas que cada vez más y con más fuerza recibe de parte de jóvenes y estudiantes, paralelas al avance de las tecnologías de información. 


\section{Referencias}

Acosta Silva, A. (2014), "Gobierno universitario y comportamiento institucional", Revista de Pedagogía, 66(1), pp. 31-44.

Albornoz, M. (2007), "Los problemas de la ciencia y el poder", Revista Iberoamericana de Ciencia, Tecnología y Sociedad, 1, pp. 47-65.

Boaventura de Sousa, S. (2017), Democracia y transformación social, México, Siglo XXI.

Broto, A. (2012), "Financiamiento y políticas públicas para las universidades nacionales en el período 20032011", en Raquel San Martín (ed.), Financiamiento de la universidad. Aportes para el debate, Buenos Aires, Universidad de Palermo, pp. 193-227.

Buchbinder, P. (2005), Historia de las universidades argentinas, Buenos Aires, Editorial Sudamericana.

Coraggio, L. (2003), "El papel de la teoría en la promoción del desarrollo local (Hacia el desarrollo de una economía centrada en el trabajo)", en José Luis Coraggio, La gente o el capital. Desarrollo local y economía del trabajo, Buenos Aires, Espacio editorial.

Del Bello, J.C. (2012), "La política de financiamiento estatal del sistema universitario argentino: planificación, funcionamiento real y una agenda de temas pendientes", en Raquel San Martín (ed.), Financiamiento de la universidad. Aportes para el debate, Buenos Aires, Universidad de Palermo, pp. 14-35.

Emiliozzi, S. (2012), "Políticas en ciencia y tecnología y universidad en Argentina: análisis sobre la formación e inserción de los recursos humanos calificados", Ponencia presentada a las VII Jornadas de Sociología de la UNLP, Buenos Aires.

Fernández Lamarra, N. (2015), La innovación en las universidades nacionales. Aspectos endógenos que inciden en su surgimiento $y$ desarrollo, Buenos Aires, Universidad Nacional Tres de Febrero.

Follari, R. (2015), "Las ciencias sociales en la encrucijada actual", Polis Revista Latinoamericana, 14 (41), pp. 147157.

García de Fanelli, A. M. (2012), "Financiamiento universitario y calidad: luces y sombras en veinte años de política pública en la Argentina”, en Raquel San Martín (ed.), Financiamiento de la universidad. Aportes para el debate, Buenos Aires, Universidad de Palermo, pp. 2158.

García de Fanelli, A. M. (2011), "Financiación de la educación superior argentina: cambios y continuidades entre los noventa y la primera década del 2000", Revista de Educación Superior y Sociedad (ESS), vol. 16, núm. 1, pp. 16-36.

García de Fanelli, A. M. (2005), Universidad, organización e incentivos, Buenos Aires, Miño y Dávila.

Gibbons, M. (1998), "Pertinencia de la educación superior en el siglo XXI", Documento presentado como una contribución a la Conferencia Mundial sobre la Educación Superior de la UNESCO, en 1998, Consulta online <http://www.humanas.unal.edu.co/ contextoedu/docs_sesiones/gibbons_vi ctor_manuel. pdf> [Consulta: febrero de 2019].

González, G. (2013), "El gobierno territorial de la educación superior: el rol del Consejo de Planificación Regional en el área metropolitana y bonaerense (19962011)", Tesis de Doctorado en Educación, Buenos Aires, Universidad de San Andrés.

González, G. y J. Claverie (2017), "Planeamiento de la educación superior en Argentina: entre las políticas de regionalización y los procesos de innovación universitaria (1995-2015)", Archivos Analíticos de Políticas Educativas, 25(70), <http://dx.doi.org/10.14507/ epaa.25.2804> [Consulta: 18 de febrero, 2019].

Honorable Congreso de la Nación (2005), Ley 26.075, Buenos Aires, Honorable Congreso de la Nación.

Honorable Congreso de la Nación (1995), Ley 24.521, Buenos Aires, Honorable Congreso de la Nación.

Honorable Congreso de la Nación (1990), Ley Ley 23.877, Buenos Aires, Honorable Congreso de la Nación.

Honorable Congreso de la Nación (1981), Ley 22.426, Buenos Aires, Honorable Congreso de la Nación. 
Lundvall, B. A. (1992), Sistemas nacionales de innovación, Londres, Pinter Publisher.

Instituto Nacional de Estadística y Censo (INDEC) (2010), Censo Nacional de Población, Hogares y Vivienda 2010, Buenos Aires, INDEC.

Martínez Porta, L. (2014), "Universidad y territorio. La universidad como agente de desarrollo local", Tesis de Maestría en Políticas Públicas, Buenos Aires, Universidad de San Andrés.

Marx, V. (2008), "Las ciudades como actores políticos en las relaciones internacionales", Tesis Doctoral, Barcelona, Universidad Autónoma de Barcelona, Facultad de Ciencias Políticas y Sociología.

Mazzucato, M. (2016), El Estado emprendedor, Londres, RBA Editorial.

Ministerio de Educación, <www.me.gov.ar>.

Presidencia de la Nación (1994), Decreto 2329/94, Buenos Aires, Presidencia de la Nación.

Presidencia de la Nación (1996), Decreto 1660/96, Buenos Aires, Presidencia de la Nación.

Presidencia de la Nación (2004), Decreto 204/2004, Buenos Aires, Presidencia de la Nación.

Rama, G. (2006), "La tercera reforma de la educación superior en América Latina y el Caribe: masificación, regulaciones e internacionalización”, en Informe sobre la educación superior en América Latina y el Caribe. La metamorfosis de la educación superior, Caracas, IESALC, UNESCO.
Rama, G. (2015), Nuevas dinámicas de la regionalización de la educación universitaria en América Latina, Buenos Aires, Universidad de Palermo.

Sábato, J. y N. Botana (1968), "La ciencia y la tecnología en el desarrollo futuro de América Latina", Revista de la Integración, (3), pp. 20-63.

Secretaria de Políticas Universitarias (SPU) (2016), Anuario nacional de estadísticas universitarias, Buenos Aires, Ministerio de Educación de la Nación.

Secretaria de Políticas Universitarias (SPU) (2013), Anuario nacional de estadísticas universitarias, Buenos Aires, Ministerio de Educación de la Nación.

Subirats, J. (2016), El poder de lo próximo. Las virtudes del municipalismo, Barcelona, Catarata.

Taquini, A. et al. (2014), Nuevas universidades para un nuevo país, Buenos Aires, Editorial Dunken.

Trippl, M. y A. Tödtling (2007), Developing biotechnology clusters in non high technology regions: the case of Austria. Industry and Innovation, Londres, Taylor and Francis.

Vasen, F. (2008), "Regulación tecnológica y valores sociales: un estudio del caso farmacéutico", en Scientiae Studia (Sao Paulo), 6(3), jul-sep, pp. 6-29.

Vasen, F. (2012), "Priorities, solidarity and the 'Watering Can': research policies and conceptions of relevance in a Latin American traditional university setting", International Fournal of Contemporary Sociology, 49(1), pp. 189-215.

\section{Cómo citar este artículo:}

González, Giselle y Cecilia Schneider (2020), "Más allá de la Torre de Marfil: vinculaciones de la universidad y sus territorios", Revista Iberoamericana de Educación Superior (RIES), vol. XI, núm. 31, pp. 24-47, DOI: https://doi.org/10.22201/iisue.20072872e.2020.31.704 [Consulta: fecha de última consulta]. 